\title{
Candor and Integrity in Science
}

\section{Citation}

Holton, Gerald. 2005. Candor and integrity in science. Synthese 145, no. 2: 277-294.

\section{Published Version}

http://dx.doi.org/10.1007/s11229-005-3749-0

\section{Permanent link}

http://nrs.harvard.edu/urn-3:HUL.InstRepos:3228039

\section{Terms of Use}

This article was downloaded from Harvard University's DASH repository, and is made available under the terms and conditions applicable to Other Posted Material, as set forth at http:// nrs.harvard.edu/urn-3:HUL.InstRepos:dash.current.terms-of-use\#LAA

\section{Share Your Story}

The Harvard community has made this article openly available.

Please share how this access benefits you. Submit a story.

\section{Accessibility}


[MS requested for publication by the journal Syntheses]

\title{
Candor and Integrity in Science
}

\author{
by Gerald Holton \\ 358 Jefferson Laboratory \\ Harvard University \\ Cambridge, MA 02138 \\ holton@physics.harvard.edu \\ (C) Copyright Gerald Holton, 2002
}

\begin{abstract}
In the pursuit of researches and in the reporting of their results, the individual scientist as well as the community of fellow professionals rely implicitly on the researcher embracing the habit of truthfulness, a main pillar of the ethos of science. Failure to adhere to the twin imperatives of candor and integrity will be adjudged intolerable and, by virtue of science's self-policing mechanisms, rendered the exception to the rule. Yet both as philosophical concepts and in practice, candor and integrity are complex, difficult to define clearly, and difficult to convey easily to those entering on scientific careers. Therefore it is useful to present operational examples of two major scientists who exemplified devotion to candor and integrity in scientific research.
\end{abstract}

When scientists communicate with one another, they may be sometimes reticent on details, for example, about painfully acquired methods still needed in their current research, or about matters that have not yet been settled finally in their own minds or laboratories. But they rarely are not candid in what they convey to colleagues or even rivals in their field. For in scientific research there is a mechanism at work that may get one found out rapidly for improbity-a mechanism and an ethos much attenuated in most other professions (as the daily news tends to make clear, be they concerning politics, the military, industrial enterprises, the public media, lawyers, financial gurus, accountancies, even the priesthood). That mechanism is the ability of sufficiently trained, skeptical scientists to confirm or deny in principle, and sometimes quite quickly in fact, the veracity of a communication offered to them.

Thus, while scientists are generally born no better or worse with respect to the general human tendencies to exaggerate or to deny, to misremember or to avoid sharing everything they know quite freely, in the acculturation process they learn to suppress those natural instincts, and try to put on what Jacob Bronowski named "the habit of truth," which is the key for the successful program of science as a whole. To be sure, when a nuclear scientist is asked about the details of a particle accelerator that is still being built, she may not always be forthcoming, but at least will reply quite appropriately-perhaps: "Sorry, I can't tell you yet"-a negative sort of candor.

Candor, of the positive or negative kind, is not the same as integrity; but the two notions are related, as indicated in my copy of Roget's Thesaurus, where both notions are listed under "probity," together with rectitude, honesty, loyalty, truth, scrupulosity, and the like. Perhaps I can here illustrate each, and the 
interplay between them, in terms of two historical examples of major scientists: one from the thoughts and works of P. W. Bridgman, the other from those of Niels Bohr, respectively experimenter and theoretician. They also may serve as actual case studies in a collection that may concentrate more on the abstract notions.

1.

Percy W. Bridgman (1882-1961) won the 1946 Nobel Prize in Physics for his investigations of the changes in materials subjected to extremely high pressures. He is also widely remembered for his contributions to the philosophy of science, which changed the intellectual landscape of many scientists. His philosophy of "operationalism," first elaborated in The Logic of Modern Physics (1927), attempted to brush away undefinable elements by proposing that concepts should be defined in terms of experimental procedures, or operationsan approach that influenced economics and psychology also.

I had the privilege of knowing Bridgman, first as his dissertation student in experimental high-pressure physics, and then as a colleague. It seems to me that his life and work were constructed along about half a dozen ordering ideas. Watching him at work, one might have been reminded of Michael Faraday: in the simplicity of the experiment and the thoroughness of detail of the research accomplished with it. When I first entered Bridgman's laboratory at Harvard, fresh from doing wartime research with advanced pulse circuits, I was astounded to see nothing but DC electrical measurements of resistances and potentials, and Kelvin Bridges instead of electronics. Yet the experiments-on tiny samples the size of a nail paring, conducted inside small presses that were themselves inside bigger presses, and all the information on the changing physical properties coming out on one wire to an old galvanometer-were topdrawer.

The work Bridgman did was always personal, hands on, faster and with more data points per day than seemed humanly possible. He said "physics is the quantitative exploration and analysis of physical experience." Those words meant what they said: quantitative, exploration, experience. He was guided not by fashionable new theories but by thermodynamics, and the prospect of huge areas of new physical phenomena to be conquered. He gave the impression of wanting to harvest field upon field of new data while keeping his eye on yet more remarkable ones constantly appearing on the horizon as he increased the pressure range. And one could rely on his every word. It even went beyond that, as I discovered when, after his death, I was asked to archive his laboratory notebooks. And there I found that in the interest of not misleading anyone, he had kept himself from publishing the last decimal in each reading, that being the region where uncertainties could enter.

Like some other scientists I have studied, Bridgman saw no fundamental difference between science and philosophy if properly conceived, nor really between his life and his work, nor between public and private science. He made no distinction between a novice with interesting ideas and willingness to work and take risks and an elder statesman of science on a courtesy visit. He seemed to be curious about every subject in science and outside, but by the same token, he was never satisfied that he had really exhausted any deep question. He would not have been surprised to learn that his own extensive work (seven 
technical books and some 200 scientific papers, plus seven more books and about 60 papers on philosophy and the study of social science) is useful today in a great variety of natural sciences-physics, chemistry, geology, engineering, even in biology, as in the study of the properties of protein under high pressure-as well as in psychology, economics, philosophy, and history of science.

Bridgman loyally stayed with his university from the day he entered as a freshman in 1900 until he retired from his professorship 54 years later. He persisted in the same field of research throughout, and saw it grow in power as he reluctantly drove the range of attainable pressures in his laboratory from a few thousand atmospheres at the start, to ultimately over 400,000. The same persistence came out in the short run as in the long. A famous example is a sentence from one of his scientific papers, describing how to make a thin hole as narrow as the lead in a pencil, but in a big block of very hard steel: "It is easy, if all precautions are observed, to drill a hole . . 17 inches long, in from 7 to 8 hours."

Anyone who knew him can immediately see him, wearing his well-used lab coat, at the lathe or at the forepump of the press, pumping up the pressure, always by hand, undeflectable by anything while taking data. I can attest to that. On a morning in the fall of 1946, I was in the workshop, constructing apparatus for my dissertation problem, which he had agreed to supervise as long as I would not bother him too often. The telephone rang, and I happened to be the one to take it. A voice from the Associated Press asked me to bring Mr. Bridgman to the phone. (Bridgman, of course, did not tolerate a telephone in his laboratory.) I explained it was impossible to get him out while he was taking data. The voice at the other end, now quite agitated, demanded an interview with him because the announcement had just come from Stockholm that Bridgman had won the Nobel Prize. Of course I ran into Bridgman's lab to convey the great news. Not missing a single stroke, he continued at the pump and said quite simply, "Tell them--I'll believe it--when I see it." Here indeed was the operational approach in action, and also a test of the equanimity of his spirit.

Plato said that "clear ideas drive away fantastic ideas," but in Bridgman the need to clarify his ideas in honest self-evaluation was not merely therapeutic, it was a biological necessity. He had an ethos of lucidity and candor of the most difficult kind: with himself. In 1938, at the peak of his powers, he wrote, "As I grow older, a note of intellectual dissatisfaction becomes an increasingly insistent overtone in my life. I am becoming more and more conscious that my life will not stand intellectual scrutiny, and at the same time my desire to lead an intelligently well-ordered life grows to an almost physical intensity."

So for Bridgman, another all-too-frequent barrier was removed-that between moral and intellectual issues. Compelled by his insistence to be clear and candid about one's stand, and acting visibly as a citizen-scientist, he published a manifesto in Science (Bridgman 1939) in which he announced closing his laboratory to visiting scientists of totalitarian countries, because he saw that they had subordinated their loyalty to science to the demands authoritarian governments might make on their work. But we also see in the preceding quotation a mainspring, a force driving several apparently disparate achievements. His attractions to high-pressure physics seem to have started with his attempt to give instrumental meaning to the concept of high hydrostatic pressures inside a sealed enclosure. He never tolerated the use of "black boxes" 
that required the experimenter to believe a manufacturer's calibration or circuit diagram. His work on dimensional analysis was in the nature of a selfinterrogation. His book on thermodynamics starts with the question, "What are the most basic variables to choose and how do we define them?"

Bridgman may not have read Charles S. Peirce's essay of 1878, "How to Make Our Ideas Clear," but he had a deeply rooted affinity with the American empiricist philosophers. Here, too, was the source of his sympathy with the philosophy of the displaced Vienna Circle, as brought by refugee scientists and philosophers who began to come to the United States in the 1930s. ${ }^{1}$

The Logic of Modern Physics (1927) was his first major contribution to the critical analysis of the foundations of physics. To this day, anyone with scientific interest who reads it for the first time finds it an electrifying experience. As must be true for many, I clearly remember the exact place in the library where, as a student, I happened upon the book, and then found myself standing there, reading the first chapters right away. Key phrases burn in one's memory: "In general, we mean by any concept nothing more than a set of operations; the concept is synonymous with the corresponding set of questions." Or, "The true meaning of a term is to be found by observing what a man does with it, not by what he says about it." Or, "If a specific question has meaning, it must be possible to find operations by which answers may be given to it. It will be found in many cases that the operations cannot exist, and the question therefore has no meaning."

All the traits of Bridgman's mind were there: the lucidity of style, the lack of philosophical self-consciousness, the uncompromising drive to the foundations. It was a message of immense power for scientists, at least in the English-speaking world, and as in many such cases, the explanation of its power is not that the book brings to the reader a message never thought of before, but rather that it lays open, with clarity, what the reader has been trying to formulate on his or her own. The most fruitful way of understanding Bridgman's philosophical writings is to see them as a record of continual self-interrogation and self-discovery. That is why they have also been such an effective tool of selfrecognition for other scientists.

It is not surprising that Bridgman had to clarify for himself philosophical problems before he could feel satisfied with his solution of scientific problems. For the typical task of science, to put it very simply, is to relate the world of appearances, or data, and the world of conceptions, or ideas. And the usual way scientists do this is to construct an arch that starts from the ground of direct observation, then rises up to the region of theory, or concepts and other thought constructs, and then comes again back to the level of the immediately given, to a new set of verifiable observations.

The question that always nags the honest mind is this: how can one be sure whether or not the arch connecting initial and final data is not merely fantasy? Roughly, Bridgman's answer was that there are two tests. There must be formal connections among the thought elements in the upper region; they must be able to stand the tests of logic and of "mental" or "paper-and-pencil" operations. And second, each of the physical concepts used must, in principle, be supported from the world of experience below, by having meaning in terms of physical or instrumental operations. This is how the operational attitude determines the shape and direction of a possible theory and the type of data 
relevant to it at each end. But this process of construction is, of course, not restricted only to science. In Bridgman's straightforward way, he wrote: "It would doubtless conduce greatly to clarity of thought if the operational mode of thinking were adopted in all fields of inquiry." Even so, the critique and elaboration of his conceptions by other scholars sometimes astonished Bridgman. Once, at the end of a long symposium with philosophers, he said, with unusual candor:

As I listened to the papers I felt that I have only a historical connection with this thing called 'operationalism' .... I have created a Frankenstein, which has certainly got away from me. I abhor the word operationalism...which seems to imply a dogma, or at least a thesis of some kind. This thing I have envisaged is too simple to be dignified by so pretentious a name; rather, it is an attitude or point of view generated by continued practice of operational analysis ....

The date usually associated with this is 1927 , the year of publication of my book, The Logic of Modern Physics, but preparation for this in my own thinking went back at least to 1914, when the task of giving two advanced courses in electrodynamics was suddenly thrust upon me .... The underlying conceptional situation in this whole area seemed very obscure to me and caused me much intellectual distress, which I tried to alleviate as best I could .... The dimensional situation proved comparatively simple, and I was able to think the situation through to my own satisfaction - an experience that perceptibly increased my intellectual morale. $^{2}$

In this quotation there is, I believe, a clue to Bridgman's key motivation. It is the sentence, "I was able to think the situation through to my own satisfaction." To clear his own ever-active mind of intellectual disquietude and the possibility of self-deception - that was a basic driving force, whether designing an experiment or analyzing the foundations of thermodynamics or of society. He never bothered to answer seriously the charge of philosophical solipsism, but I think that the answer has to be this: One cannot, by any other criterion, hope to get maxims that are more generally valid than those one can get by letting questions rise up in a mind that habitually subjects itself to exceptional intellectual disquietude, and that habitually is given to uncompromising, candid self-examination.

First and last, his science was his individual struggle to discern "the way things are," which phrase is, in fact, the title of one of his last books. Indeed, he told me he had preferred to call this book "The Way It Is. " But, he said, "the publisher doesn't like it; however, I am still not sure that 'things' really exist." To him, the mark of a scientist was the willingness to devote oneself fully to finding out the way it is, regardless of the consequences.

2.

As we saw, Bridgman placed the highest value on the most difficult way of achieving veracity: trying at all costs to be clear and honest in his own minda paradigmatic case of internal candor. His direct, plain-spoken, unambiguous writings and speeches were a result of that clearing of his own mind. Turning now to Niels Bohr (1885-1962), we find, by contrast, a rather different situation. Bohr's writings were usually the result of a painful struggle, sometimes lasting for many years of drafting and redrafting, to put into the languages of science 
and everyday speech his complex thoughts, and yet many of these publications and public addresses were, as he knew, difficult to unpuzzle. I had the opportunity to discuss this problem with him. He explained it to me in a moving sentence: "I do not chose to speak or write more clearly than I think." In this case, candor consisted in conveying with honesty the insufficiency of ordinary language to represent fully the internal state of a superb mind. However, as if to make up for this difficulty, Bohr became the paradigmatic example of the twinbrother of candor-namely, integrity.

Again, first a brief overview of his scientific career. It is commonly agreed that it may be divided roughly into five periods. During the first decade of his professional life, his main concern was with spectra, the absorption and emission of light, the structure of the periodic table, and the chemical properties of matter. During the second period, from the early 1920s for about a decade, he was the leader of his Institute for Theoretical Physics in Copenhagen, devoting himself to the conquest of quantum mechanics, working with furious energy, and surrounded by a remarkable group of young scientists from all over the world. This was the time of concern with the wave-particle puzzle, the uncertainty relation, complementarity, the discovery of the loss of visualizable physics, and the clarification of problems ranging from the structure of crystals to the chemical bond. By the late 1920s, it seemed that in principle all properties of atoms and molecules were understandable by the single force of electromagnetism.

In the third period, from the early 1930s until the occupation of Denmark by the Germans in April 1940, Bohr and his collaborators worked on what came to be known as field quantization, elementary particle physics, and the structure of the atomic nucleus. After Bohr's narrow escape from Denmark to Sweden in 1943, followed by his trip to England and then to the United States, his career entered a fourth phase as he consulted with the British scientists, and later with those at Los Alamos, who had entered upon the huge effort to preempt the German attempt to make a nuclear weapon-an attempt on which the Germans, as recent documentation shows, had in fact embarked first. But at the same time Bohr also became more and more concerned with planning for the postwar world, including his tragically unsuccessful efforts to open the eyes of Roosevelt, Churchill, and later of the United Nations leadership to opportunities that might well have averted the nuclear arms race.

In his last twenty years, Bohr was chiefly occupied with applying the lessons of his science not only to further research in physics but to all spheres of life, ranging from philosophy to international politics. He also devoted himself to the internationalization of scientific cooperation, as in the founding of CERN, the European center for research in high-energy physics, and to encouraging scientists in third-world countries.

Studying Bohr's work and life, I see four principles of integrity in science that possessed him to the end, four principles that can be emulated in our time. The first of these is simply this: Try to get it right at all costs, sparing no effort. You may have to seek help and advice where possible; but do all you can to prove to yourself and others that your scientific idea is correct. This norm or principle of integrity of science in the narrowest interpretation of the phrase can nevertheless be very hard, and may even drive one to the edge of despair if one has selected a really worthy problem. I have been surprised how often the word "despair" comes up in the autobiographies and letters of some of our best 
scientists. Heisenberg once recalled his collaboration with Bohr in 1926 and 1927, saying "We couldn't doubt that this [quantum mechanics] was the correct scheme, but even then we didn't know how to talk about it. [These discussions] threw us into a state of almost complete despair"(Heisenberg 1975, 569). ${ }^{3}$

Obedience to this norm can force one to take risks on behalf of a hard-won scientific idea before it is fashionable or safe. Again, Bohr's life and work contain many powerful illustrations. On arriving in Manchester, he soon saw that Ernest Rutherford's idea of a nuclear atom was right, and moreover that the atom "seemed to be regulated from inner part to the outer by the quantum." ${ }^{4}$ This recognition immediately became the basis of Bohr's first great work. But think what it entailed at the time. Although Rutherford himself was at the first Solvay Congress in 1911, nobody mentioned his discovery of the nucleus during that summit meeting of the major physicists of the day. It took a few more years, including Bohr's and Henry Moseley's work, for scientists to catch on generally. But Bohr had staked everything on it at once, and on the quantum ideas of Planck and Einstein that also were only beginning to be accepted by physicists. The result was the "Bohr atom" in Bohr's paper of 1913. It has long ago made its way into all the schoolbooks, but the reception at the time was quite different. Otto Stern is reported to have remarked, "If this nonsense is correct, I will give up being a physicist." Bohr said later, "There was even a general consent that it was a very sad thing that the literature about spectra should be contaminated by a paper of that kind." 5 The risk young Bohr took in his 1913 paper could well have endangered his career. It was a physics so very different from that of Newton, Maxwell, Planck, Thomson, and even Rutherford.

It is a part of the first principle of integrity that one must submit oneself to the dialogue with others to find out whether one is right. New science starts in the head of an individual, but it does not survive unless it becomes part of the consensus of the community. Bohr knew this well. When his mentor Rutherford received Bohr's paper in manuscript, he agreed to sent it on to be published despite his objections, but he wrote to Bohr, "I suppose you have no objection to my using my judgment to cut out any matter I may consider unnecessary in your paper?" (Moore 1985, 50).

Poor Rutherford! A considerably extended version of the earlier manuscript was already on its way to him, and soon thereafter Bohr himself appeared at his door, having come from Denmark where he had gone to establish himself. For many long evenings they discussed every point. Bohr reported that at the end, Rutherford declared he had not realized Bohr would prove so obstinate, but "he consented to leave all the old and new points in the final paper"(French and Kennedy 1985, 79). Then Bohr went to Göttingen and Munich, and succeeded in bringing some of the older, skeptical physicists around.

That Einstein never gave in to the Copenhagen view on quantum mechanics was to Bohr a source of real unhappiness. Indeed, very few others escaped Bohr's almost missionary zeal. His collaborators such as Leon Rosenfeld were overawed by Bohr's unrelenting effort to attain clarity of fundamentals. Bohr's favorite quotation was from Schiller: "Only fullness leads to clarity / And truth lies in the abyss." To gain the real treasures one must be ready to descend into the abyss, that dangerous place at the bottom where two huge slopes (representing contrary theories) push against each other. 
3.

I have already begun to move into the second of the principles of integrity in science. It concerns the difference between choosing the narrowly specialized problems - relatively safe but at the cost of a fragmenting and disintegrating tendency for the subject-versus choosing the more difficult problem that has some promise to bring coherence to the field, and with it integrity in the second sense of that word. To put it succinctly, the second principle might run as follows: Try to be a scientist first, a specialist second. If you have it in you to make more than individual bricks that others might use, throw your life's energies into work on what Einstein called the great temple of science.

Again, Niels Bohr can give us all the examples we need, even in his 1913 paper, where he introduced the correspondence principle in its early form precisely in order to connect quantum physics with classical physics in the limit of large orbits. It is a powerful bridge that Bohr used to great advantage for years, for example for the theory of stopping fast-moving particles in matter, in his 1948 survey. Similarly he dealt with the puzzle of light and matter for over two decades, trying ways to reconcile the discontinuity shown by quantum effects with the continuity shown in classical physics.

Dealing with science in a coherent way also led him to think about scientific fields far beyond physics, in a manner that few had dared to do since the days of Helmholtz and Ernst Mach. He struggled constantly with what he called "the epistemological lesson which the modern development of atomic physics has given us, and its relevance for [the other] fields of human knowledge"(Bohr 1961, v). One chief lesson of quantum mechanics was that atomic processes did not have to be described in fragmentary ways, with different theories for different effects, but that through quantum mechanics we could see the wholeness of the processes in and among atoms.

Could this lesson not be applied to wider fields? Bohr thought it could. Therefore his essays dealt often with "biological and anthropological problems," stressing the features of wholeness distinguishing living organisms and human cultures-at least insofar as such "problems present themselves against the background of the general lesson of atomic physics"(Bohr 1961, 2).

To some extent, Bohr's pursuit of the second principle was part of the old hope of the "unity of all sciences," a phrase he often used. But it is not merely a phrase, an empty dream. That the various branches of science form one organic, interlocking picture of the world shows up in almost any substantial scientific research today. A modern paper on cosmology is really a jigsaw puzzle of which the pieces might well carry individually such labels as "elementary particle physics," "general relativity," "applied mathematics," and "observational astronomy." An experiment in neurophysiology brings together physics, chemistry, biology, computer technology, mathematics, and engineering, all at once. Such examples are becoming the rule. As Bronowski wrote, "Science is not a set of facts, but a way of giving order and therefore giving unity and intelligibility to the facts of nature"(Bronowski 1956).

If Bohr himself did not work directly in fields outside the physical sciences, he did persuade some of his younger collaborators. A major example is Max Delbrück, who gladly confessed that the prime motivation of his own early work in biology was "Niels Bohr's suggestion of the complementarity principle 
in biology as a counterpart to the complementarity principle in physics"(Kay 1985).

4.

As we come to the third principle of integrity in science, as exemplified in Bohr's life and work, the area of action, opportunity, and obligation for the responsible scientist widens still further, and so does the challenge to follow Bohr's example. Both the findings of modern science and its "habit of truth to experience" have penetrated deeply into the world of culture as a whole. The third principle of integrity in science might go like this: "Science is, and should be, part of the total world view of our time. This is a vision you should imaginatively explore, defend, and contribute to."

There are various ways of implementing such a vision, and Niels Bohr was active in each of them. There is of course the task of pedagogy, the need to bring scientific understanding to all parts of society, not least because persons in this modern world who do not know the basic facts that determine their very existence, functioning, and surroundings are in fact living in a dream world. Such persons are, in a sense, not sane.

Then there is the link of science and policy. If that link is not understood, if the technical implications for good and ill are not made clear, democracy is at risk because the leadership can be caught up in fantasies-whether technocratic or Luddite-and the citizenry cannot participate in the basic decisions that have technical components.

But for Bohr, the third principle asserted itself also in an almost compulsive pursuit, during the last twenty years of his life, to find bridges between scientific knowledge and such nonscientific fields as ethics, the arts, and philosophy. Bohr was interested in philosophy from early youth on, looking for "great interrelationships" among all areas of knowledge. ${ }^{6}$ This ambition eventually took a different and grander form, based chiefly on the complementarity principle he announced in 1927. There are various statements of it. Bohr's own briefest formulation goes like this: "Any given application of classical concepts precludes the simultaneous use of other classical concepts which, in a different connection, are equally necessary for the elucidation of the phenomena." 7 The issue behind all this, as Robert Oppenheimer and many othershave stressed, concerns the three great overlapping questions: What is objectivity? What is reality? Is the world deterministic or not? For classical physics, it was possible to say that the world was deterministic in the sense that if the positions and momenta of all objects were precisely measured, the future course of all history would be known. But, Bohr asked, would this be true on the atomic scale? Could that world be known more and more certainly, independent of our own predilections, or decisions, or our laboratory arrangements?

As we know, Bohr, Heisenberg, and others of that circle gave a resounding "No" to that question in the 1920s. Objective knowledge of a phenomenon, in Bohr's terms, is what you learn from the full reports of all experimental arrangements that probe into the phenomenon-arrangements, be it noted, of apparatus on the scale of everyday life, and describable in ordinary human language (with mathematics merely a compact and refined extension of it). There is no firm boundary between that which is observed and the observing machinery; the boundary is movable, and the different descriptions that result from different placements of the boundary are complementary. Together they 
give an exhaustive account of whatever one means by reality. Objectivity, according to the Copenhagen school, is therefore, in Oppenheimer's phrase, not an "ontological attribute" - that is, not a description of the property of beingbut becomes a problem of communication.

Bohr saw in his complementarity principle the hope to extend the concept of complementarity beyond physics, in dealing with such opposing concepts or mutually exclusive experiences as thought and introspection, justice and charity, the processes in the living cell and the biophysical, biochemical analysis of organisms. By describing his ambitious attempt for examination, I am of course not proposing that Niels Bohr's own solution to meet the obligation of the third principle of integrity be universally adopted. Rather, I am illustrating the challenge that genius sets for itself. We scientists, in our more humble ways, should also do what we can to explore the links between the sciences and with other areas of scholarship, or we shall be pushed out of the common culture. The laboratory remains our workplace, but it must not become our hiding place.

The full grandeur of Bohr's ambition was to apply the complementarity point of view also to the understanding and toleration of differences between traditional cultural systems. What gave it all such urgency for him was his perception that the most time-honored method of conflict between societies was chiefly the attempt by one to annihilate the other, and that in the atomic age. This method had become a guarantee for universal catastrophe, for mutual suicide. As Bohr put it, the main obstacle to a peaceful relation between various human societies is "the deep-rooted differences of the traditional backgrounds...which exclude any simple comparison [or accommodation] between such cultures. It is above all in this connection that the viewpoint of complementarity offers itself as a means of coping with the situation"(Bohr 1961, 30).

He never gave up the hope that this could be achieved, although he knew it would not be done soon. In his last interview, on the day before his death, he said, "There is no philosopher who really understands what one means by the complementarity description. It has to go [into] the schools." The Copernican system was, for a long time, also not accepted by the philosophers. But eventually “the school children didn't think it was so bad. [This is how it got into] common knowledge. I think it will be exactly the same with the complementarity description." 8

5.

With this I have come to the fourth, the last and most demanding of the principles of integrity: the special obligation scientists have to exercise sound citizenship. There are many reasons why that obligation is special, and the very opposite of elitist arrogance. The most obvious one is simply this: having been helped to become scientists and to live as scientists in this suffering world, we are the beneficiaries of unusual privilege, of scarce resources, and of the painful labors of our scientific parents. The mechanics we learned in school came to birth in the anguish of Galileo, dictating his book in his old age, disgraced, blind, and under house arrest. Kepler died on a highway like a dog, on one of his futile journeys to find money to pay for printing the books from which we have learned about his laws. Indeed, many of the formulas we rely on every day were distilled from the blood and sweat of our distant forebears, most of them now 
forgotten. We stand not only on the shoulders of a few, but also at the graves of thousands.

Science by its nature is cumulative and consensual, a social activity across space and time. In addition, any new scientific finding has the potential of changing, sooner or later, some part of the life of mankind, and not in every case for the better. Under these circumstances one must conclude that science has a just claim to moral authority when it is widely seen as an activity that honors both truth and the public interest. By this I do not mean that each individual scientist must be active beyond science on behalf of the welfare of society, as were Bohr and Bridgman in their different ways. But I do mean that when we look over the profession as a whole we must be able to say that this group, through the activities of enough of its members, is responding to its special responsibilities--special for all the reasons I have given, but also because on certain issues our scientific knowledge does give us an opportunity to make essential policy suggestions. ${ }^{9}$ And special too, some may wish to add, simply because the flow of so much good brain power into science and technology today may have caused a corresponding deficit or opportunity cost in the rest of the polity.

Here again, Niels Bohr is an exemplar of the good citizen within the republic of science. This came through in so many ways, earliest perhaps by his openness to and encouragement of new talent, no matter from where it came. But from the many illustrations we must finally select the example he gave us through his dedication to oppose the arms race.

More than most others, Bohr thought of the atomic bomb not only as decisive in countering any such German effort: as his memoranda to President Roosevelt and later his letter to the United Nations show, Bohr also thought of such weapons as ending at last the tolerability of war itself. Thus he wrote, "The expectations for a future harmonious international cooperation...remarkably correspond to the unique opportunities which...have been created by the advancement of science"(Bohr 1985). For this to happen, as he saw very clearly, one had to preempt a nuclear arms race after World War II. To achieve that, in turn, meant capturing the energies of the world's scientists, as well as of the atom itself, for peaceful purposes. And that inevitably meant we would need an "open world," for the verification of arms control agreements, for sharing technical information for peaceful uses, and also for sharing more in one another's cultures.

The main stumbling block, he knew well, would be dealing properly with the Soviet Union. Often invaded, and again deeply ravaged by war, its citizens viewed themselves as a great nation, beleaguered but not to be coerced. To avoid a fatal increase in hostility and suspicion on their part, Bohr argued again and again in 1944 and early 1945 that one would have to bring them in before the end of the war, while they were still allies, to reach an understanding of the world's common interests, including the industrial uses of atomic energy, based on concessions on each side.

Bohr saw a unique opportunity before the full development and deployment of a new weapons system, an opportunity in which historically based rivalries and contrary traditions could be submerged and their negative potential defused. He urged also that scientists of different countries, used to international collaboration and having bonds across national frontiers, could 
prove especially helpful with the deliberations of their respective governments. Finally, he hoped that the world's political leadership would contain sufficiently many statesmen to whom scientists could speak on such matters and who would understand them.

We know of course how very differently it all came out. In early 1944 Churchill and, at his urging, Roosevelt agreed that the Soviet leadership be faced with a fait accompli of the atomic bomb's development. Thereby they were betting that secrecy was really working, and that any Soviet buildup of a similar system later on would be slow. Neither turned out to be true. Incidentally, they also agreed that Bohr should be carefully watched because of his eager interest in international collaboration on arms control. If it had been up to Churchill alone, Bohr would probably have been interned after Bohr visited Churchill in an attempt to convert him to Bohr's view.

Scholars will debate for years whether a break through the fears on both sides, and particularly through the alienation of Stalin and his circle (about whom Bohr had no illusions), could have resulted from the vision of a harmonious and progressive world which Bohr urged. With his usual eloquence, Robert Oppenheimer summed up the hopeful view in these words: "I think that if we had acted wisely and clearly and discreetly, in accordance with Bohr's views, we might have been freed of our rather sleazy sense of omnipotence, and our delusions about the effectiveness of secrecy, and turned our society toward a healthier vision of a future worth living for"(Oppenheimer). Even as yet other potentially destabilizing weapon systems are being designed, these words should remind us how fatefully the world today is facing a moment of history that has close analogies to the situation then. And once more, as Niels Bohr and others have shown at similar points, the moral authority of scientists as citizens will be tested by the seriousness, courage, and eloquence with which they inform the current debate.

With candor and integrity in mind, when our students and colleagues inquire about probity in science, let us tell them of Bridgman and Bohr. Let us tell them that such probity is not achieved merely through fear of sanctions against dishonor, but must be earned through positive acts: acts motivated by thorough intellectual self-examination and the adoption of the merciless habit of truth; motivated by some understanding of the grand history of our science, and of our privileged place in it; motivated by the scope and seriousness of the quest as scientists; motivated by the hope that science will help build a coherent world picture; and not least motivated by our responsibilities, as citizen-scientists, to the larger society that has nourished us, the society which we must help to flourish, or with which we shall perish.

\section{ACKNOWLEDGMENT}

Portions of this article have been adapted from my essay, "A Personal View of Percy W. Bridgman, Physicist and Philosopher," Methodology and Science, 26:01 (1993), and from Chapter 12 of my Thematic Origins of Scientific Thought: Kepler to Einstein, rev. ed. (Harvard University Press, Cambridge, MA, 1988).

\section{NOTES}


[Ed.: insert end notes here]

\section{REFERENCES}

American Institute of Physics: 1962, interviews with Niels Bohr, in Sources for the History of Quantum Physics (on deposit, unpublished).

Bohr, N.: 1961, Atomic Physics and Human Knowledge, Science Editions, New York.

Bohr, N.: 1985, 'The Ideal of an Open World', Impact of Science on Society 35, 30 (reprint of letter of June 9, 1950).

Bridgman, P. W.: 1933, 'The Struggle for Intellectual Integrity', in Bridgman, P. W.: 1955, Reflections of a Physicist, $2^{\text {nd }}$ ed., Philosophical Library, New York, pp. 361-379.

Bridgman, P. W.: 1939, 'Manifesto by a Physicist', Science 89,179.

Bridgman, P. W.: 1961, 'The Present State of Operationalism', in Frank, P. G. (ed.), The Validation of Scientific Theories, Collier Books, New York.

Bronowski, J.: 1956, 'The Educated Man in 1984', Science 123, 710.

Einstein, A.: 1949, 'Autobiographical Notes', in Schilpp, P. A. (ed.), Albert Einstein: Philosopher-Scientist, Library of Living Philosophers, Evanston, Il.

French, A. P. and Kennedy, P. J. (eds.): 1985, Niels Bohr: A Centenary Volume, Harvard University Press, Cambridge, Mass.

Heisenberg, W. : 1975, 'Discussion with Heisenberg', in Gingerich, O. (ed.), The Nature of Scientific Discovery, Smithsonian Institution Press, Washington, D. C.

Holton, G.: 1998, The Advancement of Science, and Its Burdens, Harvard University Press, Cambridge, Mass.

Holton, G.: 1993, Science and Anti-Science, Harvard University Press, Cambridge, Mass.

Holton, G.: 1995, 'On the Vienna Circle in Exile: An Eyewitness Report', in Köhler, E. et al. (eds.), The Foundation Debate, Kluwer, Dordrecht, pp. 269292.

Kay, L. E.: 1985, 'Conceptual Models and Analytical Tools: The Biology of Physicist Max Delbrück', Journal of the History of Biology 18, 207.

Moore, R.: 1985, Niels Bohr: The Man, His Science, and the World They Changed, MIT Press, Cambridge, Mass.

Oppenheimer, R.: 'Niels Bohr and His Times', The George B. Pegram Lectureship, Brookhaven, NY, Oppenheimer Collection, Box 267, Library of Congress, Washington, D. C.

Sonnert, G. and Holton, G.: 2002, Ivory Bridges: Connecting Science and Society, MIT Press, Cambridge, Mass.

Wheeler, J.: 1963, 'Fugitive and Cloistered Virtue', Physics Today 16, 30. 
${ }^{1}$ For the transplantation of elements in the Vienna Circle to the U.S., and Bridgman's role in it, see Holton 1993, chapter 1, and Holton 1995.

${ }^{2}$ Bridgman 1961, pp. 75-76, a work first published in Boston by Beacon Press in 1954. Bridgman also published an article entitled "The Struggle for Intellectual Integrity" in Harper's Magazine in December, 1933, which is reprinted in Bridgman 1955.

${ }^{3}$ On Einstein's case of "despair," see Einstein 1949, pp. 51-53.

${ }^{4}$ Interview 1 with Bohr, October 31, 1962, p. 10, in American Institute of Physics 1962.

${ }^{5}$ Interview 2 with Bohr, November 7, 1962, p. 1, in American Institute of Physics 1962.

${ }^{6}$ See Moore 1985, pp. 406-407. For another example, see the discussion of Einstein's search for a coherent world picture in Holton 1998, chapter 4.

${ }^{7}$ Quoted in Wheeler 1963.

${ }^{8}$ Session 5 with Bohr, November 17, 1962, in American Institute of Physics 1962.

${ }^{9}$ Remarkably, many of the best scientists have collaborated, without relying on a call from the government, to form organizations through which citizen-scientists can promote the welfare of society. Profiles of several dozen of these are to be found in the new book Sonnert and Holton 2002. Bohr and Bridgman each helped to found one of these organizations. 